\begin{tabular}{|c|c|c|c|}
\hline \multirow{3}{*}{$\begin{array}{r}\text { Case Reports in } \\
\text { Gastroenterology }\end{array}$} & \multicolumn{2}{|c|}{ Case Rep Gastroenterol 2018;12:513-518 } & \multirow[b]{2}{*}{$\begin{array}{l}\text { Karger } \\
\text { Open access }\end{array}$} \\
\hline & $\begin{array}{l}\text { DOI: } 10.1159 / 000492459 \\
\text { Published online: August 28, } 2018\end{array}$ & $\begin{array}{l}\text { (c) } 2018 \text { The Author(s) } \\
\text { Published by S. Karger AG, Basel } \\
\text { www.karger.com/crg }\end{array}$ & \\
\hline & $\begin{array}{l}\text { This article is licensed under th } \\
\text { International License (CC BY-NC) } \\
\text { Usage and distribution for commer }\end{array}$ & $\begin{array}{l}\text { hons Attribution-NonCommercial } 4.0 \\
\text { ger.com/Services/OpenAccessLicense). } \\
\text { uires written permission. }\end{array}$ & \\
\hline
\end{tabular}

\title{
Arterial Pseudoaneurysm within a Pancreatic Pseudocyst
}

\author{
Veit Phillip ${ }^{a} \quad$ Rickmer Braren ${ }^{b} \quad$ Nikolaus Lukas ${ }^{c} \quad$ Roland M. Schmid $^{a}$ \\ Fabian Geisler ${ }^{a}$ \\ aKlinik und Poliklinik für Innere Medizin II, Klinikum rechts der Isar der Technischen \\ Universität München, Munich, Germany; 'blnstitut für Diagnostische und Interventionelle \\ Radiologie, Klinikum rechts der Isar der Technischen Universität München, \\ Munich, Germany; 'CKlinik für Innere Medizin I, Klinikum Freising, akademisches \\ Lehrkrankenhaus der Technischen Universität München, Freising, Germany
}

\section{Keywords}

Pseudoaneurysm · Pancreatic pseudocyst

\begin{abstract}
The formation of pancreatic pseudocysts and (pseudo-)aneurysms of intestinal vessels are rare but life-threatening complications in acute and chronic pancreatitis. Here we report the rare case of a patient suffering from chronic pancreatitis with an arterial pseudoaneurysm within a pancreatic pseudocyst and present its successful therapeutic management by angioembolization to prevent critical bleeding. A 67-year-old male with a history of chronic pancreatitis presented with severe acute abdominal pain and vomiting to the emergency department. Seven weeks prior to the present admission, a CT scan had displayed a pancreatic pseudocyst with a maximum diameter of $53 \mathrm{~mm}$. A laboratory examination revealed an elevated white blood cell count $\left(15.40 \times 10^{3} / \mu \mathrm{L}\right)$, as well as elevated serum lipase $(191 \mathrm{U} / \mathrm{L})$, bilirubin $(1.48 \mathrm{mg} / \mathrm{dL})$, and blood glucose (353 mg/dL) levels. Sonographically, the previously described pancreatic pseudocyst revealed a slightly increased maximum diameter of $65 \mathrm{~mm}$ and an inhomogeneous echo of the cystic content. A contrast-enhanced CT scan showed a further increase in maximum diameter to $70 \mathrm{~mm}$ of the known pseudocyst. Inside the pseudocyst, a pseudoaneurysm originating from the splenic artery with a maximum diameter of $41 \mathrm{~mm}$ was visualized. After interdisciplinary consultation, prophylactic coil embolization of the splenic artery was immediately performed. The pseudoaneurysm was shut off from blood supply by back-door/front-door
\end{abstract}


occlusion employing 27 coils, resulting in complete exclusion of the pseudoaneurysm from the circulation. Pseudoaneurysms are a rare complication of acute and chronic pancreatitis which has been shown to be efficiently treated by coil embolization.

(c) 2018 The Author(s)

Published by S. Karger AG, Basel

\section{Introduction}

Pancreatic pseudocyst formation is a well-known complication in chronic and acute pancreatitis that can cause local complications and pain. The prevalence of pseudocysts among patients with chronic pancreatitis approximates $20-40 \%$; however, this may be overestimated due to changes in the nomenclature of peripancreatic fluid collections in the revised Atlanta classification $[1,2]$. In patients with acute pancreatitis, the development of a pancreatic pseudocyst is extremely rare and usually occurs delayed after $>4$ weeks [2]. Pancreatic pseudocysts are defined as localized fluid collections in (peri-)pancreatic tissue which contain a fluid rich in pancreatic enzymes without any solid material and have a well-defined, nonepithelialized wall consisting of fibrous and granulated tissue. They are to be distinguished from acute peripancreatic fluid collections, acute necrotic collections, and walled-off necrosis. Diagnoses can usually be made based on morphologic criteria [2, 3].

Another complication in patients suffering from acute or chronic pancreatitis is the formation of (pseudo-)aneurysms of intestinal vessels, a rare but life-threatening complication if bleeding of the pseudoaneurysm occurs, with a mortality of 30-50\% [4-10]. The formation of (pseudo-)aneurysms and arrosions of vessels are triggered by inflammation of the pancreas and the surrounding tissue, extravasation of proteolytic enzymes, formation of pseudocysts, extensive necrosis, or abscesses [11,12].

Here we report the clinical case of a patient with an arterial pseudoaneurysm within a pancreatic pseudocyst and show the prophylactic therapy to prevent critical bleeding.

\section{Case Report}

A 67-year-old male with a 3.5-year history of chronic alcoholic pancreatitis presented with severe acute abdominal pain and vomiting to the emergency department of a teaching hospital. The patient had experienced a first episode of acute alcoholic pancreatitis 7 years previously, and at least three subsequent acute attacks of chronic pancreatitis within the last 3.5 years. Seven weeks prior to the present admission, he had suffered from the last acute attack, and a CT scan revealed a pancreatic pseudocyst at the pancreatic tail with a maximum diameter of $53 \mathrm{~mm}$. There was no indication for intervention at that time. The patient reported an alcohol intake of 1-2 L of beer per day and hard liquor intake once a month as well as regular cigarette smoking (45 pack-years). The patient was on oral anticoagulation due to atrial fibrillation and had been suffering from arterial hypertension and insulin-dependent diabetes mellitus for 3.25 years. He reported reduced enteral food intake due to abdominal pain, particularly postprandially, and a weight loss of $20 \mathrm{~kg}$ (24\%) within the previous 12 months without night sweat.

On admission, a blood pressure of 190/89 mm Hg and a regular heartbeat (56 bpm) were measured. He had no fever, his body height was $180 \mathrm{~cm}$, and his body weight $62 \mathrm{~kg}$ (BMI 19.1). 
Laboratory examination revealed an elevated white blood cell count $\left(15.40 \times 10^{3} / \mu \mathrm{L}\right)$, as well as elevated serum lipase (191 U/L), bilirubin $(1.48 \mathrm{mg} / \mathrm{dL})$, and blood glucose (353 $\mathrm{mg} / \mathrm{dL}$ ) levels. The international normalized ratio was 1.2.

Sonographically, the previously described pancreatic pseudocyst revealed a slightly increased maximum diameter of $65 \mathrm{~mm}$ and an inhomogeneous echo of the cystic content (Fig. $1 \mathrm{a}, \mathrm{b})$. Color-coded Doppler sonography showed a turbulent blood flow in parts of the cyst (Fig. 1c).

The patient was transferred to our tertiary care center for further evaluation and therapy. A contrast-enhanced CT scan at admission (Fig. 2) showed multiple calcifications in the head and body of the pancreas, as well as an irregularly widened pancreatic duct as signs of a chronic pancreatitis. There were no signs of an acute pancreatitis. The known pseudocyst showed a further increase in maximum diameter to $70 \mathrm{~mm}$ (arrows). Inside the pseudocyst, a pseudoaneurysm originating from the splenic artery with a maximum diameter of $41 \mathrm{~mm}$ was visualized (asterisk), classified as type IIA2 [13]. After interdisciplinary consultation, prophylactic coil embolization of the splenic artery was immediately performed to prevent spontaneous bleeding. The splenic artery was accessed via a right transfemoral approach (Fig. 3ac). The pseudoaneurysm was shut off from blood supply by back-door/front-door occlusion employing 27 coils, resulting in complete exclusion of the pseudoaneurysm from the circulation (Fig. 3d).

Six weeks after coil embolization, a control CT scan showed a stable condition of the pseudocyst without any signs of reperfusion of the pseudoaneurysm or of infection. There were no signs of infarction of the spleen, with good arterial circulation arising from strong collaterals.

\section{Discussion}

In this case report, we described the very rare situation of an arterial pseudoaneurysm within a pancreatic pseudocyst in a patient suffering from chronic pancreatitis and report on its successful, prophylactic therapy to prevent critical bleeding.

Pancreatic pseudocysts often do not need any therapy, as up to $60 \%$ of them resolve spontaneously [14]. In case of complications such as abdominal pain, jaundice, splenic vein thrombosis, infection, or impression of the stomach with early satiety, weight loss, and nausea/vomiting, drainage might be indicated $[1,15]$. According to a recent review, endoscopic ultrasound-guided drainage is the optimal drainage approach in uncomplicated pseudocysts that are located adjacent to the stomach or duodenum. However, radiologic or surgical drainage might be indicated in complicated cases.

Regarding intestinal pseudoaneurysms, the optimal therapeutic strategy, including arterial embolization and surgical procedures, is still controversial $[9,10]$. Nevertheless, based on the widespread availability and minimal invasiveness, contrast-enhanced CT and digital subtraction angiography have been widely used to detect visceral arterial bleeding sites. Furthermore, due to the improved technical capabilities of interventional radiology, angioembolization should be considered as the first-line therapy to stop the bleeding in patients with bleeding pseudoaneurysms $[9,10]$. Due to the infrequency of arterial pseudoaneurysms, data on diagnostics and prophylactic therapy to prevent bleeding are rare. Arterial pseudoaneurysms in pancreatitis are associated with nonspecific symptoms, requiring a high degree of suspicion for an early diagnosis [16]. An individualized diagnostic approach combining sound anamnesis, thorough clinical examination, and technical approaches such as endoscopic ultrasound, 


\section{Case Reports in Gastroenterology}

CT, or MRI are mandatory. According to the sparse literature on this topic, endovascular intervention is highly effective and should be the preferred treatment option $[17,18]$.

\section{Statement of Ethics}

Written informed consent was obtained from the patient.

\section{Disclosure Statement}

All authors have no conflict of interest to declare.

\section{References}

1 Ramsey ML, Conwell DL, Hart PA. Complications of Chronic Pancreatitis. Dig Dis Sci. 2017 Jul;62(7):1745-50.

2 Banks PA, Bollen TL, Dervenis C, Gooszen HG, Johnson CD, Sarr MG, et al.; Acute Pancreatitis Classification Working Group. Classification of acute pancreatitis - 2012: revision of the Atlanta classification and definitions by international consensus. Gut. 2013 Jan;62(1):102-11.

3 Lambiase LR, Anand BS, Greenwald D. Pancreatic Pseudocysts. Medscape; 2017.

4 Andersson E, Ansari D, Andersson R. Major haemorrhagic complications of acute pancreatitis. Br J Surg. 2010 Sep;97(9):1379-84.

5 Carr JA, Cho JS, Shepard AD, Nypaver TJ, Reddy DJ. Visceral pseudoaneurysms due to pancreatic pseudocysts: rare but lethal complications of pancreatitis. J Vasc Surg. 2000 Oct;32(4):722-30.

6 White AF, Baum S, Buranasiri S. Aneurysms secondary to pancreatitis. AJR Am J Roentgenol. 1976 Sep;127(3):393-6.

7 Hsu JT, Yeh CN, Hung CF, Chen HM, Hwang TL, Jan YY, et al. Management and outcome of bleeding pseudoaneurysm associated with chronic pancreatitis. BMC Gastroenterol. 2006 Jan;6(1):3.

8 El Hamel A, Parc R, Adda G, Bouteloup PY, Huguet C, Malafosse M. Bleeding pseudocysts and pseudoaneurysms in chronic pancreatitis. Br J Surg. 1991 Sep;78(9):1059-63.

9 Phillip V, Rasch S, Gaa J, Schmid RM, Algül H. Spontaneous bleeding in pancreatitis treated by transcatheter arterial coil embolization: a retrospective study. PLoS One. 2013 Aug;8(8):e72903.

10 Chiang KC, Chen TH, Hsu JT. Management of chronic pancreatitis complicated with a bleeding pseudoaneurysm. World J Gastroenterol. 2014 Nov;20(43):16132-7.

11 Flati G, Salvatori F, Porowska B, Talarico C, Flati D, Proposito D, et al. Severe hemorrhagic complications in pancreatitis. Ann Ital Chir. 1995 Mar-Apr;66(2):233-7.

12 Flati G, Andrén-Sandberg A, La Pinta M, Porowska B, Carboni M. Potentially fatal bleeding in acute pancreatitis: pathophysiology, prevention, and treatment. Pancreas. 2003 Jan;26(1):8-14.

13 Pang TC, Maher R, Gananadha S, Hugh TJ, Samra JS. Peripancreatic pseudoaneurysms: a management-based classification system. Surg Endosc. 2014 Jul;28(7):2027-38.

14 Teoh AY, Dhir V, Kida M, Yasuda I, Jin ZD, Seo DW, et al. Consensus guidelines on the optimal management in interventional EUS procedures: results from the Asian EUS group RAND/UCLA expert panel. Gut. 2018 Jul;67(7):1209-28.

15 Braha J, Tenner S. Fluid Collections and Pseudocysts as a Complication of Acute Pancreatitis. Gastrointest Endosc Clin N Am. 2018 Apr;28(2):123-30.

16 Martins A, Gonçalves Á, Passos P, Cardoso M, Torres R, Almeida T, et al. Splenic Artery Pseudoaneurysm. J Gastrointest Surg. 2018 Jul;22(7):1297-1298.

17 Sawachika H, Fujita S, Mukai T, Morita Y. IgG4-related autoimmune pancreatitis complicated by splenic artery pseudoaneurysm. BMJ Case Rep 2018;2018. pii: bcr-2018-224589.

18 Zabicki B, Limphaibool N, Holstad MJ, Juszkat R. Endovascular management of pancreatitis-related pseudoaneurysms: A review of techniques. PLoS One. 2018 Jan;13(1):e0191998. 


\section{Case Reports in Gastroenterology}
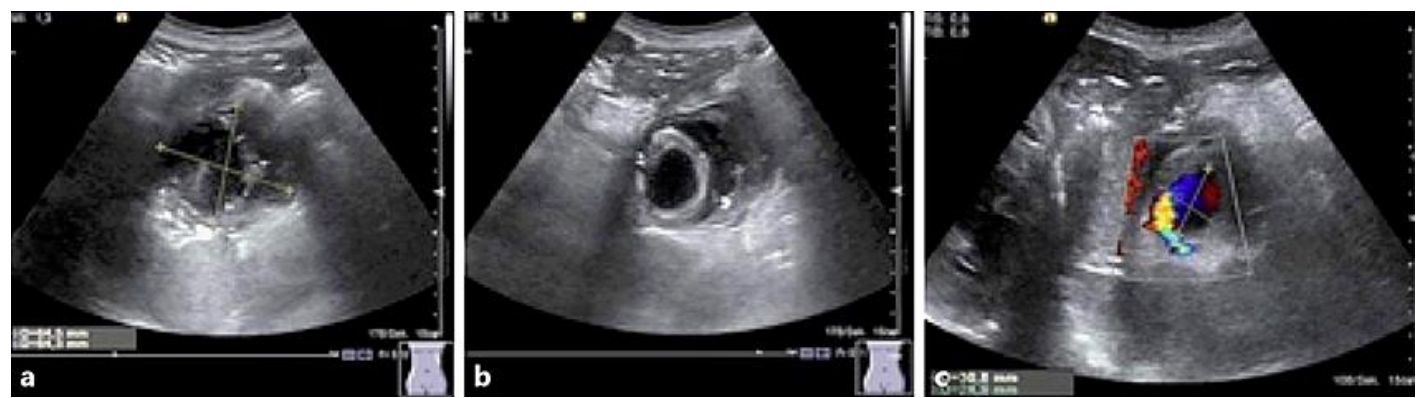

Fig. 1. a, b Transabdominal ultrasound showing a pancreatic pseudocyst with a maximum diameter of 65 $\mathrm{mm}$ and an inhomogeneous echo of the cystic content. c Color-coded Doppler sonography showed a turbulent blood flow in parts of the cyst.

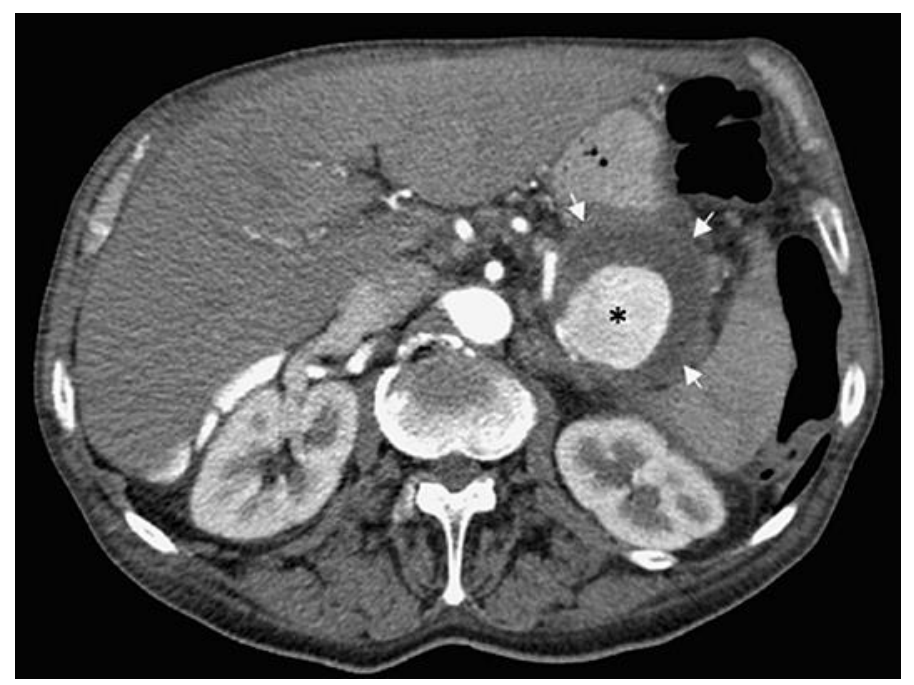

Fig. 2. Contrast-enhanced CT scan showing a pancreatic pseudocyst with a maximum diameter of $70 \mathrm{~mm}$ (arrows). Inside the pseudocyst is a pseudoaneurysm originating from the splenic artery with a maximum diameter of $41 \mathrm{~mm}$ (asterisk). 


\section{Case Reports in Gastroenterology}
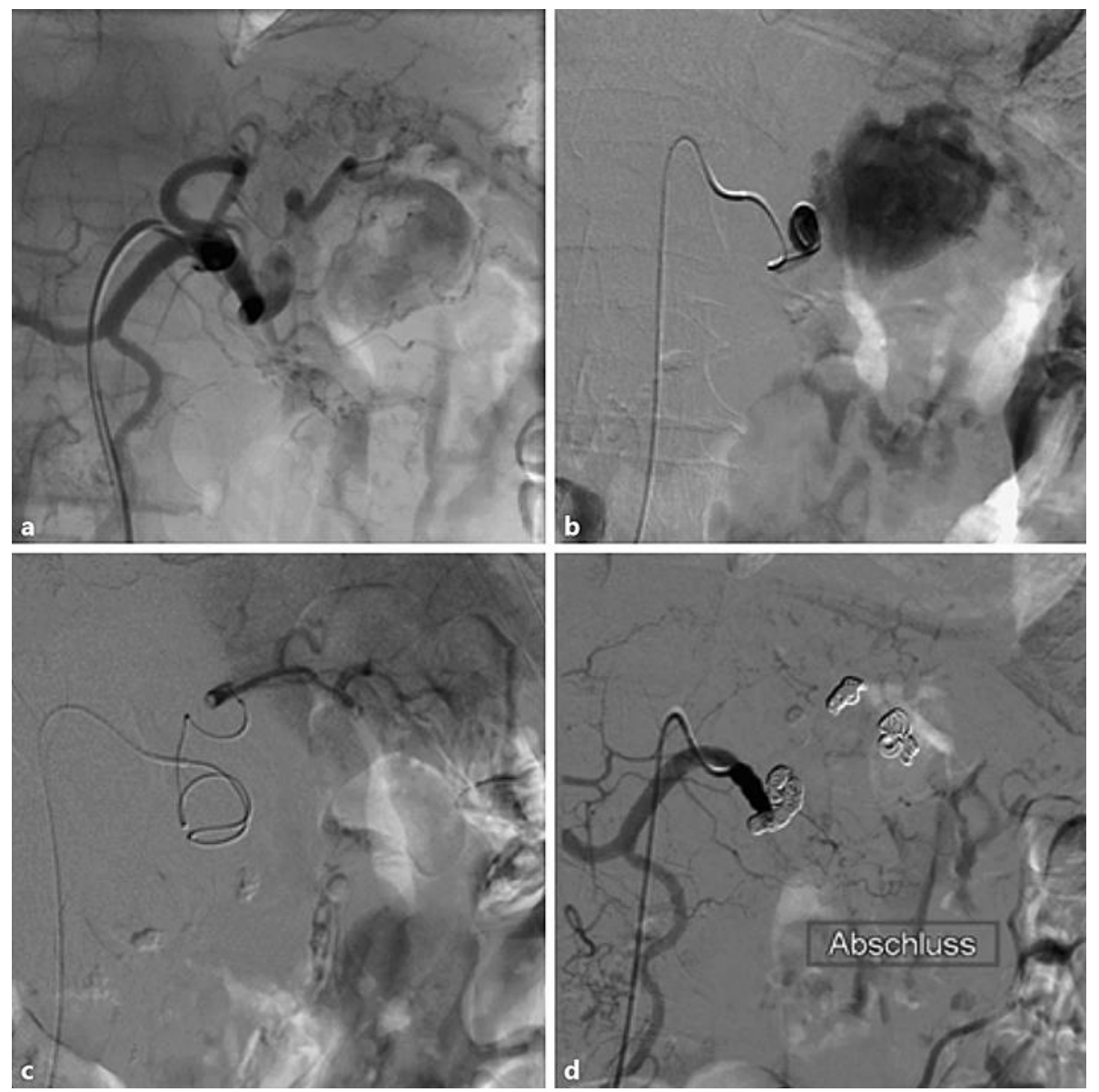

Fig. 3. a-c Digital subtraction angiography with a right transfemoral access showing the splenic artery and a pseudoaneurysm. $\mathbf{d}$ The pseudoaneurysm was shut off from blood supply by back-door/front-door occlusion employing 27 coils, resulting in complete exclusion of the pseudoaneurysm from the circulation. 